\title{
Maternal low-protein diet-induced delayed reflex ontogeny is attenuated by moderate physical training during gestation in rats
}

\author{
Filippe Falcão-Tebas ${ }^{1 *}$, Adriano Bento-Santos ${ }^{2}$, Marco Antônio Fidalgo ${ }^{3}$, Marcelus Brito de Almeida ${ }^{3}$, \\ José Antônio dos Santos ${ }^{2}$, Sandra Lopes de Souza ${ }^{1,2}$, Raul Manhães-de-Castro ${ }^{1,2}$ \\ and Carol Góis Leandro ${ }^{1,3}$ \\ ${ }^{1}$ Department of Nutrition, Federal University of Pernambuco, Rua Prof. Moraes Rego, 1235, CEP 50670-901, \\ Recife, PE, Brazil \\ ${ }^{2}$ Department of Neuropsychiatry and Behavioral Science, Federal University of Pernambuco, Recife, PE, Brazil \\ ${ }^{3}$ Department of Physical Education and Sports Science, CAV - Federal University of Pernambuco, Recife, Brazil
}

(Received 7 January 2011 - Revised 4 April 2011 - Accepted 27 April 2011 - First published online 4 July 2011)

\begin{abstract}
We evaluated the effects of moderate- to low-intensity physical training during gestation on reflex ontogeny in neonate rats whose mothers were undernourished. Virgin female Wistar rats were divided into four groups as follows: untrained (NT, $n$ 7); trained (T, $n$ 7); untrained with a low-protein diet $(\mathrm{NT}+\mathrm{LP}, n 7)$; trained with a low-protein diet $(\mathrm{T}+\mathrm{LP}, n$ 4). Trained rats were subjected to a protocol of moderate physical training on a treadmill over a period of 4 weeks $\left(5 \mathrm{~d} /\right.$ week and $60 \mathrm{~min} / \mathrm{d}$, at $65 \%$ of $\left.\mathrm{VO}_{2 \max }\right)$. After confirming the pregnancy, the intensity and duration of the exercise were reduced. Low-protein groups were provided with an $8 \%$ casein diet, and controls were provided with a $17 \%$ casein diet. Their respective offspring were evaluated (during the 10th-17th days of postnatal life) in terms of physical feature maturation, somatic growth and reflex ontogeny. Pups born to mothers provided with the low-protein diet during gestation and lactation showed delayed physical feature and reflex maturation and a deficit in somatic growth when compared with controls. However, most of these deficiencies were attenuated in pups of undernourished mothers undergoing training. In conclusion, physical training during gestation attenuates the effects of perinatal undernutrition on some patterns of maturation in the central nervous system during development.
\end{abstract}

Key words: Brain: Pregnancy: Exercise: Low-protein diet: Wistar rats

It has been well established that insults, such as malnutrition, during the critical period of development of the nervous system can have noticeable impacts on the development of brain structure and function, resulting in developmental dysfunctions and diseases in later life $\mathrm{e}^{(1)}$. A perinatal low-protein diet is associated with impaired cerebral vascularisation and reduced dendrite numbers in the rat offspring ${ }^{(2)}$. Human infants born with fetal intra-uterine growth restriction have reduced hippocampal volume, which has been associated with functional behavioural differences ${ }^{(3)}$.

The reflex maturation pattern, 'a behaviour elicited by exactly prescribed stimulation', is used to demonstrate an appropriate maturation of the central nervous system during development ${ }^{(4)}$. Using this model, our previous study demonstrated a delay in the maturation of reflexes, as well as deficits in locomotion patterns caused by postnatal malnutrition in neonatal rats ${ }^{(5)}$. In addition, reductions in protein or energy intake during the perinatal period may influence feeding behaviour and locomotor activity in adult rats ${ }^{(5,6)}$. Such structural and functional changes in the brains of the offspring may be due to changes in cerebral metabolism, reduced nutrients in placental space or reduced oxygen consumption by dams ${ }^{(7)}$.

Recently, it has been recognised that an active maternal lifestyle, including regular-to-moderate physical activity, improves aerobic fitness and the maternal-fetal physiological reserve by enhancing nutrient and oxygen availability to the fetus $^{(8)}$. In the nervous system, maternal exercise during pregnancy has beneficial effects on brain functions and structures of both mother and offspring ${ }^{(9)}$. In rats, exercise during pregnancy increases the expression of brain-derived neurotrophic factor hippocampal mRNA and spatial learning in rat pups ${ }^{(10)}$. Maternal treadmill running during pregnancy (30 min at a mild intensity, once a day until delivery) enhanced hippocampal cell survival and improved the

Abbreviations: NT, untrained rats; $\mathrm{NT}_{\mathrm{L}}$, litters of untrained rats; $\mathrm{NT}+\mathrm{LP}$, untrained rats with a low-protein diet; $\mathrm{NT}+\mathrm{LP}_{\mathrm{L}}$, litters of untrained rats with a low-protein diet; $\mathrm{T}$, trained rats; $\mathrm{T}_{\mathrm{L}}$, litters of trained rats; $\mathrm{T}+\mathrm{LP}$, trained rats with a low-protein diet; $\mathrm{T}+\mathrm{LP} \mathrm{P}_{\mathrm{L}}$, litters of trained rats with a low-protein diet. 
short-term memory capability of pups of rats compared with the control group ${ }^{(11)}$. A human study showed that mothers who trained during gestation showed better self-esteem and a lower incidence of depression during pregnancy, and their offspring showed fewer signs of stress during delivery and were in better general condition (as evidenced by higher Apgar scores) ${ }^{(9)}$.

In our previous study, we demonstrated that in rats, a controlled moderate-to low-intensity exercise before and during gestation $(5 \mathrm{~d} /$ week and $60 \mathrm{~min} / \mathrm{d}, \quad 40-70 \%$ of $\mathrm{VO}_{2 \max }$ ) attenuated the impact of the low-protein diet by improving the mothers' resting oxygen consumption ${ }^{(12)}$. In the present study, the impact of the moderate-to-low protocol of physical training during gestation on the reflex ontogeny in neonates whose mothers were undernourished, was evaluated. Our hypothesis was that exercise-induced protective changes in the brain during gestation attenuate the impact of a low-protein diet on somatic development and reflex ontogeny in the offspring.

\section{Methods}

The experimental protocol was approved by the Ethics Committee of the Biological Sciences Center (protocol no. 23076.049077/2010-80), Federal University of Pernambuco, Recife, PE, Brazil, and we followed the Guidelines for the Care and Use of Laboratory Animals ${ }^{(13)}$.

\section{Animals}

Virgin female albino Wistar rats (Rattus norvegicus), $60 \mathrm{~d}$ old, were obtained from the Department of Nutrition, Federal University of Pernambuco, and were maintained at a room temperature of $22 \pm 1^{\circ} \mathrm{C}$ with a controlled light-dark cycle (dark 06.00-18.00 hours). The animals were given standard laboratory chow (52\% carbohydrate, $21 \%$ protein and $4 \%$ lipids - Nuvilab CR1-Nuvital ${ }^{\circledR}$; Curitiba, Parana, Brazil) and water ad libitum. The animals were randomly divided into two groups: untrained rats (NT, $n$ 14) and trained rats (T, $n$ 11). The trained rats were submitted to a training programme of moderate running over a period of 4 weeks $(5 \mathrm{~d} /$ week and $60 \mathrm{~min} / \mathrm{d})$ on a treadmill (EP-131 ${ }^{\circledR}$; Insight Equipments, São Paulo, Brazil) at a controlled intensity based on their $\mathrm{VO}_{2 \max }{ }^{(12)}$. After a 4-week training period, the rats were mated (two females for one male). The day on which spermatozoa were present in a vaginal smear was designated as the day of conception, day 0 of pregnancy. Pregnant rats were then transferred to individual cages. Half of the rats of each group received ad libitum a $17 \%$ casein diet, and the other half received an $8 \%$ casein isoenergetic diet (low-protein group, LP; Table 1). Thus, two more groups were formed as follows: untrained (NT, $n$ 7); trained (T, $n 7$ ); untrained with low-protein diet (NT + LP, $n$ 7); trained with low-protein diet $(\mathrm{T}+\mathrm{LP}, n 4)$. The exercise programme was maintained during gestation, with a progressive reduction in intensity until day 19 of gestation ${ }^{(12)}$. During the suckling period, the offspring were maintained as litters of six pups, and their mothers continued to be provided with the respective diet
Table 1. Composition of the diets (control, 17\%; low-protein diet, $8 \%$ )

\begin{tabular}{lcc}
\hline & \multicolumn{2}{c}{ Amount for $1 \mathrm{~kg}$ of diet } \\
\cline { 2 - 3 } Ingredients & Low-protein diet & Control \\
\hline Casein & $79.3 \mathrm{~g}$ & $179.3 \mathrm{~g}$ \\
Vitamin mix & $10 \mathrm{~g}$ & $10 \mathrm{~g}$ \\
Mineral mixturet & $35 \mathrm{~g}$ & $35 \mathrm{~g}$ \\
Cellulose & $50 \mathrm{~g}$ & $50 \mathrm{~g}$ \\
Choline bitartrate & $2.5 \mathrm{~g}$ & $2.5 \mathrm{~g}$ \\
DL-Met & $3.0 \mathrm{~g}$ & $3.0 \mathrm{~g}$ \\
Soya oil & $70 \mathrm{ml}$ & $70 \mathrm{ml}$ \\
Maize starch & $750.2 \mathrm{~g}$ & $650.2 \mathrm{~g}$ \\
\hline
\end{tabular}

* Vitamin mixture contained the following ( $\mathrm{mg} / \mathrm{kg}$ of diet): retinol, 12; cholecalciferol, 0.125; thiamin, 40; riboflavin, 30; pantothenic acid, 140; pyridoxine, 20; inositol, 300; cyanocobalamin, 0.1; menadione, 80; nicotinic acid, 200; choline, 2720; folic acid, 10; p-aminobenzoic acid, 100; biotin, 0.6.

† Mineral mixture contained the following (mg/kg of diet): $\mathrm{CaHPO}_{4}, 17200 ; \mathrm{KCl}$, 4000; $\mathrm{NaCl}, 4000 ; \mathrm{MgO}, 420 ; \mathrm{MgSO}_{4}, 2000 ; \mathrm{Fe}_{2} \mathrm{O}_{2}, 120 ; \mathrm{FeSO}_{4} \cdot 7 \mathrm{H}_{2} \mathrm{O}, 200$; trace elements, $400\left(\mathrm{MnSO}_{4} \cdot \mathrm{H}_{2} \mathrm{O}, 98 ; \mathrm{CuSO}_{4} \cdot 5 \mathrm{H}_{2} \mathrm{O}, 20 ; \mathrm{ZnSO}_{4} \cdot 7 \mathrm{H}_{2} \mathrm{O}, 80\right.$ $\mathrm{CoSO}_{4} \cdot 7 \mathrm{H}_{2} \mathrm{O}, 0 \cdot 16 ; \mathrm{KI}, 0.32$; sufficient starch to bring to $40 \mathrm{~g}$ (per kg of diet)).

of either $8 \%$ casein or $17 \%$ casein. The litters of six pups represent the sample that was evaluated: untrained $\left(\mathrm{NT}_{\mathrm{L}}, n 7\right)$; trained $\left(\mathrm{T}_{\mathrm{L}}, n 7\right)$; untrained with low-protein diet $\left(\mathrm{NT}+\mathrm{LP}_{\mathrm{L}}\right.$, $n 7)$; trained with low-protein diet $\left(\mathrm{T}+\mathrm{LP}_{\mathrm{L}}, n 4\right)$. The evaluation of the physical characteristics, growth and reflex ontogeny of pups was performed between days 10 and 21 of the suckling period. The collection of physical characteristics and behavioural data was performed under blind conditions.

\section{Protocol of physical training}

The protocol of physical training was performed according to Amorim et al. ${ }^{(12)}$. The rats ran on a treadmill during the 4 weeks before pregnancy $(5 \mathrm{~d} /$ week and $60 \mathrm{~min} / \mathrm{d}$, at $65 \%$ $\left.\mathrm{VO}_{2 \max }\right)$. The protocol was divided into four progressive stages in each session: (i) warm-up ( $5 \mathrm{~min}$ ); (ii) intermediary (10 min); (iii) training (30 min); (iv) cool-down ( $5 \mathrm{~min}$ ) periods. The percentage of $\mathrm{VO}_{2 \max }$ during the sessions of training was kept at about $55-65 \%{ }^{(12)}$. During pregnancy, the rats ran at a progressively lower intensity of effort ( $40 \%$ $\mathrm{VO}_{2 \max }, 5 \mathrm{~d} /$ week and $20 \mathrm{~min} / \mathrm{d}$ ) until the 19th day of gestation. There was no physical training during the lactation period.

\section{Mother's body weight and food intake}

The mother's body weight was recorded daily, and daily food consumption was determined by the difference between the amount of food provided at the onset of the dark cycle (06.00 hours) and the amount of food remaining $24 \mathrm{~h}$ later $^{(6)}$. Body weight and food weight were recorded with a Marte Scale (AS-1000) with a 0.01 g accuracy.

\section{Physical feature maturation of the offspring}

The internal auditory conduit opening of both ears and eyes (i.e. when any visible break in the covering membrane of both eyes) was observed. The features were evaluated daily between 13.00 and 15.00 hours by the method of Smart \& Dobbing $^{(4)}$ during the suckling period, until maturation. 
The maturation age of a particular feature was defined as the day it was first observed.

\section{Somatic growth}

Somatic growth was assessed in terms of body weight, tail length and mediolateral and anteroposterior head axis measurements performed from the 10th to the 17 th postnatal day between 13.00 and 15.00 hours as follows: body weight of the pups was recorded daily throughout the experiment with a Marte scale with $100 \mathrm{mg}$ precision. Body weight gain was calculated as follows:

$$
\begin{aligned}
\text { Percentage weight gain }= & (\text { body weight }(\mathrm{g}) \\
& \times 100 / \text { birth weight }(\mathrm{g}))-100 .
\end{aligned}
$$

Changes in body weight ( $\Delta$ body weight) were calculated by the gain of $\mathrm{g} / \mathrm{d}^{(14)}$. Changes in body length ( $\Delta$ body length) were calculated by the gain of $\mathrm{mm} / \mathrm{d}^{(14)}$. Tail length (distance from tail tip to tail base), length of the laterolateral skull axis (distance between the ear holes) and length of the anteroposterior axis of the head (distance between snout and head-neck articulation) were measured with a digital caliper (Series 799A-12/300; Starrett ${ }^{\circledR}$, São Paulo, Brazil) with a $0.01 \mathrm{~mm}$ precision.

\section{Reflex test}

Daily examinations evaluating a spectrum of reflexological tests (Table 2) ${ }^{(15)}$ as indicators of neurological development were conducted from the 10th to the 17th postnatal days. Reflex tests were conducted between 11.00 and 13.00 hours. The time of the appearance of each reflex was defined as the first day of its occurrence during a period of three consecutive days.

\section{Statistical analyses}

Body weight and food intake of mothers are presented as means with their standard errors of the mean. Each litter of six pups was considered to be one sample, and statistical analyses were performed by using the mean values of each litter. For statistical analysis, data were analysed by two-way repeated-measures ANOVA, with mothers' diet (NT and NT $+\mathrm{LP})$ and physical training $(\mathrm{T}$ and $\mathrm{T}+\mathrm{LP})$ as factors. Bonferroni's post hoc test was used. For reflex ontogeny and physical characteristics, data are presented as median and minimal and maximal values. The Kruskal-Wallis test followed by Dunn's test (reflexes) was applied for multiple comparisons. Significance was set at $P<0 \cdot 05$. Data analysis was performed using the statistical program GraphPad Prism $5^{\circledR}$ (GraphPad Software, Inc., La Jolla, CA, USA).

\section{Results}

Gain of body mass was lower in the second and last third of gestation in the groups submitted to a low-protein diet, whereas physical training had no effect on the gain of body mass (NT, 33.9 (SEM 2.4); T, 35.9 (SEM 1.5); NT + LP, 26.9 (sem $1 \cdot 2)$; and $\mathrm{T}+\mathrm{LP}, 28.8(\operatorname{sem} 2 \cdot 1) ; P<0.05$; Fig. $1(\mathrm{a})$ ). Data were adjusted for the number of pups born to each dam (NT, 10.0 (9-12); T, 9.5 (9-13); NT + LP, 9.5 (8-10); and $\mathrm{T}+\mathrm{LP}, 10 \cdot 0(8-10)$; values expressed as medians (minimum and maximum)). Pearson's correlation coefficient between the number of pups and body weight gain of the mother was not significant $\left(r^{2} \quad 0 \cdot 29\right)$. Daily food intake during gestation and the first week of lactation was not different among the groups (Fig. 1(b)). On the second week of lactation, rats of the trained groups ingested more food, whereas groups provided with the low-protein diet ingested less food daily when compared with controls (Fig. 1(b)).

Litters from NT + LP mothers showed a deficit in the somatic growth indicators when compared with litters from the NT control group (Table 3). When compared with the $\mathrm{NT}+\mathrm{LP}_{\mathrm{L}}$ group, the $\mathrm{T}+\mathrm{LP}_{\mathrm{L}}$ group showed higher values of growth rate, tail length, laterolateral skull axis and anteroposterior axis of the head (Table 3).

During the lactation period (from 10th to 17th days of life), pups in each litter were analysed in terms of the development of physical characteristics and reflex ontogeny (Table 4). The physical features of pups from trained mothers $\left(\mathrm{T}_{\mathrm{L}}\right)$ did not change, while those of undernourished pups appeared $2 \mathrm{~d}$ later compared with the control pups. For the time of 'eyes opening', the $\mathrm{T}+\mathrm{LP}_{\mathrm{L}}$ group was not different when compared with the $\mathrm{NT}_{\mathrm{L}}$ group. Similarly, the reflex ontogeny

\begin{tabular}{|c|c|c|}
\hline Reflex & Stimulus & Response \\
\hline $\begin{array}{l}\text { Free-fall righting } \\
\text { (acceleration righting) }\end{array}$ & $\begin{array}{l}\text { Rat held by the paws, back downwards, } \\
\text { dropped from } 30 \mathrm{~cm} \text { on a cotton wool pad }\end{array}$ & $\begin{array}{l}\text { Turns body in mid-air, to land on all fours. } \\
\text { All legs must be free of body on landing }\end{array}$ \\
\hline Negative geotaxis & Rat placed with head downwards, on a $45^{\circ}$ slope & Turns to face up the slope, at least $130^{\circ}$, in $10 \mathrm{~s}$ \\
\hline Cliff avoidance & $\begin{array}{l}\text { Rat put on edge of a bench, with nose and } \\
\text { forefeet just over the edge }\end{array}$ & $\begin{array}{l}\text { Withdrawal of head and both forefeet from } \\
\text { the edge, moving away from 'cliff', in } 10 \mathrm{~s}\end{array}$ \\
\hline Auditory startle response & $\begin{array}{l}\text { Sudden sound stimulus by percussion with } \\
\text { a metallic stick in a metal surface }\end{array}$ & $\begin{array}{l}\text { Body retraction, with a transitory immobility. } \\
\text { The stimulus was given twice in each test, } \\
\text { at an interval of } 1 \mathrm{~min}\end{array}$ \\
\hline Vibrissa placing & $\begin{array}{l}\text { Rat held by the tail, head facing an edge of a } \\
\text { bench, vibrissa just touching vertical surface }\end{array}$ & $\begin{array}{l}\text { Lifts head and extends forepaws in the direction } \\
\text { of the bench, making oriented 'walking' } \\
\text { movements to go far from the edge, in } 10 \mathrm{~s}\end{array}$ \\
\hline
\end{tabular}

Table 2. Description of the reflex tests*

${ }^{*}$ According to Smart \& Dobbing. 

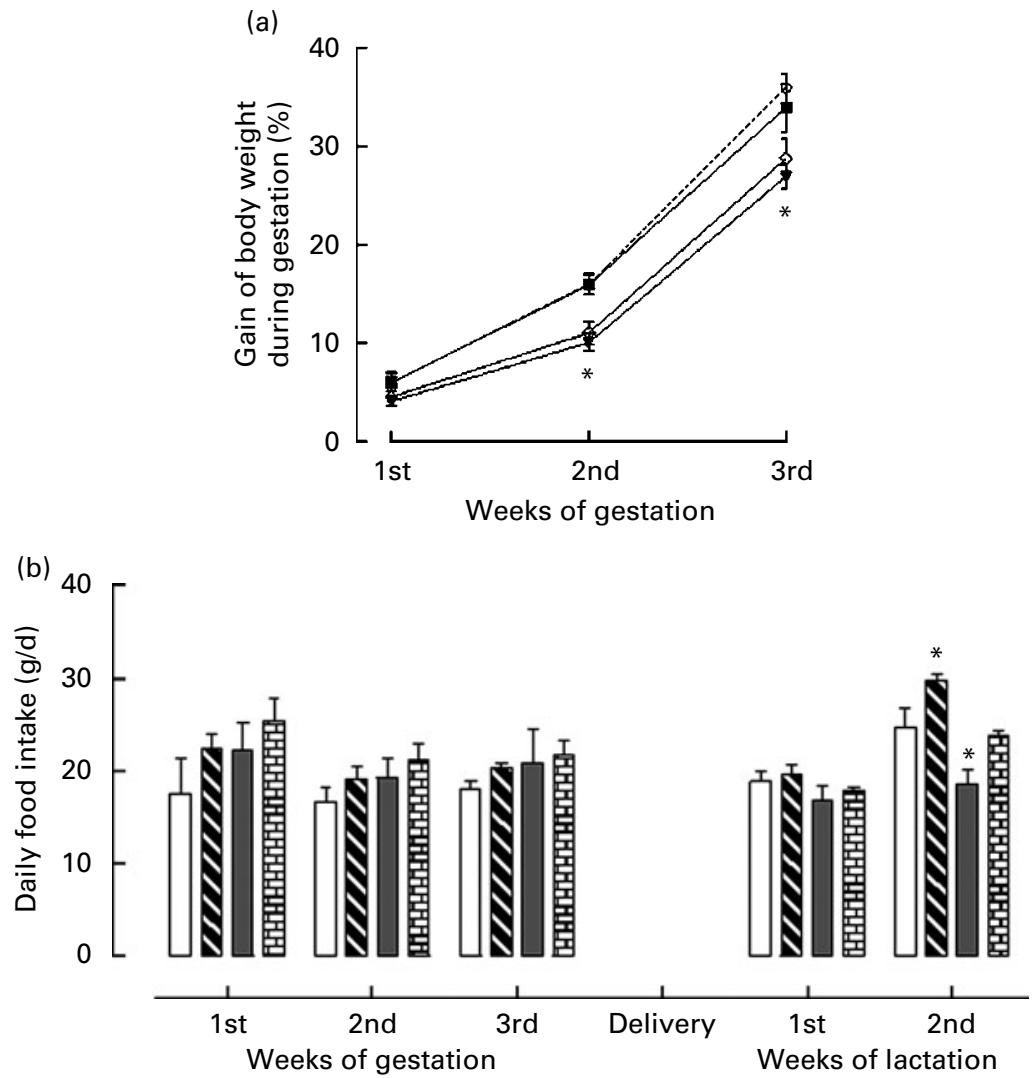

Fig. 1. Gain of body weight during gestation and food intake during gestation and lactation by untrained (NT, $n 7$ ), trained (T, $n 7$ ), untrained + low protein $(\mathrm{NT}+\mathrm{LP}, n \mathrm{7})$ and trained + low protein dams $(T+\mathrm{LP}, n 4)$. (a) Percentage of body weight gain in each third of gestation, relative to the body mass on the first

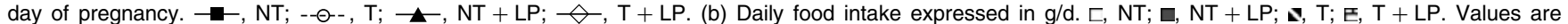
means, with their standard errors represented by vertical bars. * Mean values were significantly different from those of NT group using two-way ANOVA and Bonferroni's post hoc test $(P<0.05)$.

of pups from trained mothers did not change, while the pups from mothers provided a low-protein diet during gestation and lactation showed delayed maturation of reflexes when compared with the control $\left(\mathrm{NT}_{\mathrm{L}}\right)$ group, with the exception of the auditory startle response (Table 4). In comparison with the $\mathrm{NT}+\mathrm{LP}_{\mathrm{L}}$ group, the pups from trained and undernourished mothers $\left(\mathrm{T}+\mathrm{LP}_{\mathrm{L}}\right)$ showed an early maturation of the vibrissa placing, cliff avoidance and negative geotaxis (Table 4).

\section{Discussion}

Several studies on critical periods in brain development and the vulnerability of the developing brain to undernutrition have previously been performed ${ }^{(5,15-19)}$. Undernutrition at

Table 3. Indicators of somatic growth at 17th day of life of litters*

(Mean values with their standard errors, $n 6$ )

\begin{tabular}{|c|c|c|c|c|c|c|c|c|}
\hline & \multicolumn{8}{|c|}{ Groups $\dagger$} \\
\hline & \multicolumn{2}{|c|}{$\mathrm{NT}_{\mathrm{L}}$} & \multicolumn{2}{|c|}{$T_{L}$} & \multicolumn{2}{|c|}{$\mathrm{NT}+\mathrm{LP} \mathrm{L}_{\mathrm{L}}$} & \multicolumn{2}{|c|}{$\mathrm{T}+\mathrm{LP} \mathrm{P}_{\mathrm{L}}$} \\
\hline & Mean & SEM & Mean & SEM & Mean & SEM & Mean & SEM \\
\hline Body weight (g) & $39 \cdot 0$ & 1.1 & 33.9 & 0.9 & $19 \cdot 5^{a}$ & 0.7 & $19 \cdot 9^{a}$ & 1.0 \\
\hline Body length (mm) & 104.9 & 1.3 & 107.5 & 0.9 & $81 \cdot 0^{\mathrm{a}}$ & $1 \cdot 2$ & $86 \cdot 0^{\mathrm{a}}$ & $1 \cdot 2$ \\
\hline$\Delta$ Body weight $(\mathrm{g} / \mathrm{d})$ & $2 \cdot 8$ & 0.9 & 2.7 & 0.4 & $1 \cdot 1^{\mathrm{a}}$ & 0.1 & $1.4^{\mathrm{a}, \mathrm{b}}$ & 0.01 \\
\hline$\Delta$ Body length $(\mathrm{mm} / \mathrm{d})$ & $30 \cdot 1$ & 1.5 & $29 \cdot 7$ & 1.4 & $25 \cdot 3$ & $2 \cdot 2$ & $19 \cdot 9^{\mathrm{a}}$ & 2.6 \\
\hline Tail length (mm) & $47 \cdot 8$ & 0.4 & $44 \cdot 2$ & 1.2 & $37 \cdot 0^{\mathrm{a}}$ & 0.6 & $41 \cdot 0^{\mathrm{a}, \mathrm{b}}$ & 0.6 \\
\hline Laterolateral skull axis $(\mathrm{mm})$ & $16 \cdot 7$ & 0.06 & $16 \cdot 1$ & 0.09 & $14 \cdot 3^{\mathrm{a}}$ & 0.1 & $15 \cdot 1^{a, b}$ & 0.2 \\
\hline Anteroposterior axis of the head $(\mathrm{mm})$ & 34.3 & 0.09 & $34 \cdot 1$ & 0.1 & $30 \cdot 9^{a}$ & 0.4 & $31 \cdot 4^{a, b}$ & 0.1 \\
\hline
\end{tabular}

$N T_{L}$, litters of untrained rats; $T_{L}$, litters of trained rats; $N T+L P_{L}$, litters of untrained rats with a low-protein diet; $T+L P_{L}$, litters of trained rats with a low-protein diet.

${ }^{\mathrm{a}, \mathrm{b}}$ Mean values with unlike letters were significantly different from those of $\mathrm{NT}_{\mathrm{L}}$ and $\mathrm{NT}+\mathrm{LP} \mathrm{L}$ using two-way ANOVA and Bonferroni's post hoc test $(P<0.05)$.

* During gestation, the dams were submitted to physical training and fed a low-protein diet. During lactation, the dams remain receiving a low-protein diet. The pups into each

litter were evaluated from 10 th to 17 th day during lactation.

$\dagger \mathrm{NT}_{\mathrm{L}}, n 7 ; \mathrm{T}_{\mathrm{L}}, n 7 ; \mathrm{NT}+\mathrm{LP}_{\mathrm{L}}, n 7 ; \mathrm{T}+\mathrm{LP}_{\mathrm{L}}, n 4$. 
the time of critical development appears to depress the rates of all brain growth events ${ }^{(17)}$. In fact, our data showed that physical features, somatic growth and ontogeny reflexes are severely affected in pups from undernourished mothers. However, these undernutrition-induced alterations were less pronounced in pups whose mothers were submitted to physical training during gestation.

Maternal weight gain is the standard measure used to assess the outcome of pregnancy, and it also allows examination of the extent to which an undernourished dam is able to change body composition to maintain lactational performance ${ }^{(20)}$. In the present study, patterns of response in terms of body weight gain and food intake by undernourished mothers were similar to those of the previous studies ${ }^{(20-22)}$. During lactation, undernourished mothers showed a reduced food intake, whereas trained mothers showed an increase in food intake. Because physical training can induce an increase in maternal lean body mass, the low-protein diet-induced catabolism can be attenuated by a mechanism that includes an increase in the availability of protein ${ }^{(8)}$. In addition, maternal physical exercise seems to have a positive impact on the maternal protein reserve, thereby improving the female's ability to sustain lactation, with more protein available for mobilisation allowing increased food intake and improved lactational performance ${ }^{(23)}$.

To minimise the effects of stress from mother/pups separation, which itself has a significant impact on behavioural responses ${ }^{(24)}$, the pups were evaluated in a shortened range of time because most reflexes mature after the 10th day of life $\mathrm{e}^{(4,5)}$. Our data showed that pups from undernourished mothers were smaller than those of the controls. Furthermore, the dimensions of the head were reduced. Maternal protein restriction is associated with lower stores of maternal nutrients and, subsequently, lesser transfer of nutrients to the offspring, which is related to reduced postnatal growth ${ }^{(25)}$. Intra-uterine malnutrition also has long-term effects on brain cell number and cell size, probably via alteration in the fetal mitotic rate ${ }^{(18)}$. However, moderate exercise during gestation may have beneficial effects on the indicators of somatic growth in the offspring from undernourished mothers by a mechanism that could include increasing uterine blood flow ${ }^{(26)}$, redistributing blood flow, changes in the production of fetal and placental hormones that control growth ${ }^{(27)}$ and a higher resting oxygen consumption ${ }^{(12)}$.

The repercussions of perinatal malnutrition on the development of the structural, neurochemical and functional integrity of the nervous cells are well known ${ }^{(28)}$. In the present study, there was a delay in the appearance of physical features and most reflexes, with the exception of the auditory startle response. In a previous study using a multi-deficient diet (regional diet basic, $8 \%$ protein) during lactation, it was observed that reflexes - including free-fall righting, negative geotaxis, cliff avoidance and vibrissa placing - showed the same range of delayed days ${ }^{(5)}$. Although the different undernutrition models and the period of time (gestation, lactation or both) differed by experimental designs, one can be certain that the normal development of the brain is strictly related to balanced nutritional intake. 
Maternal physical training was able to attenuate the delayed reflex ontogeny-induced by undernutrition. The physiological mechanism can be associated with an increase in uterine blood flow, which occurs during moderate-intensity exercise, as well as with the expanded blood volume, and increased resting oxygen consumption found in response to regular exercise ${ }^{(8,12)}$. The present study suggests that exercise should be considered as a therapeutic means of countering the effects of maternal undernutrition, and that it may provide a useful strategy for enhancing the neuronal activity of children born to mothers who experience a restricted diet during pregnancy.

\section{Acknowledgements}

The authors declare no conflicts of interest. The present study was supported by CNPq and CAPES. The authors' contributions are as follows: M. A. F. and C. G. L. performed the study design. F. F.-T., A. B.-S. and J. A. d. S. performed the experiments and data collection. F. F.-T. and C. G. L. performed the statistical analyses and interpretation of the data, and wrote the paper. All authors were responsible for the critical revisions of the paper and approval of the final version. The authors are indebted to Lucia Pires and Edeones França for their technical assistance.

\section{References}

1. Dauncey MJ \& Bicknell RJ (1999) Nutrition and neurodevelopment: mechanisms of developmental dysfunction and disease in later life. Nutr Res Rev 12, 231-253.

2. Bennis-Taleb N, Remacle C, Hoet JJ, et al. (1999) A low-protein isocaloric diet during gestation affects brain development and alters permanently cerebral cortex blood vessels in rat offspring. J Nutr 129, 1613-1619.

3. Lodygensky GA, Seghier ML, Warfield SK, et al. (2008) Intrauterine growth restriction affects the preterm infant's hippocampus. Pediatr Res 63, 438-443.

4. Smart JL \& Dobbing J (1971) Vulnerability of developing brain. II. Effects of early nutritional deprivation on reflex ontogeny and development of behaviour in the rat. Brain Res 28, 85-95.

5. Barros KM, Manhaes-De-Castro R, Lopes-De-Souza S, et al. (2006) A regional model (Northeastern Brazil) of induced mal-nutrition delays ontogeny of reflexes and locomotor activity in rats. Nutr Neurosci 9, 99-104.

6. Lopes de Souza S, Orozco-Solis R, Grit I, et al. (2008) Perinatal protein restriction reduces the inhibitory action of serotonin on food intake. Eur J Neurosci 27, 1400-1408.

7. Gallagher EA, Newman JP, Green LR, et al. (2005) The effect of low protein diet in pregnancy on the development of brain metabolism in rat offspring. J Physiol 568, 553-558.

8. Clapp JF 3rd (2003) The effects of maternal exercise on fetal oxygenation and feto-placental growth. Eur J Obstet Gynecol Reprod Biol 110, Suppl. 1, S80-S85.

9. Wolfe LA \& Weissgerber TL (2003) Clinical physiology of exercise in pregnancy: a literature review. J Obstet Gynaecol Can 25, 473-483.

10. Parnpiansil P, Jutapakdeegul N, Chentanez T, et al. (2003) Exercise during pregnancy increases hippocampal brainderived neurotrophic factor mRNA expression and spatial learning in neonatal rat pup. Neurosci Lett 352, 45-48.
11. Kim H, Lee SH, Kim SS, et al. (2007) The influence of maternal treadmill running during pregnancy on short-term memory and hippocampal cell survival in rat pups. Int $J$ Dev Neurosci 25, 243-249.

12. Amorim MF, dos Santos JA, Hirabara SM, et al. (2009) Can physical exercise during gestation attenuate the effects of a maternal perinatal low-protein diet on oxygen consumption in rats? Exp Physiol 94, 906-913.

13. Bayne K (1996) Revised Guide for the Care and Use of Laboratory Animals available. American Physiological Society. Physiologist 39, 208-111.

14. Bayol S, Jones D, Goldspink G, et al. (2004) The influence of undernutrition during gestation on skeletal muscle cellularity and on the expression of genes that control muscle growth. Br J Nutr 91, 331-339.

15. Dobbing J \& Hopewell JW (1971) Permanent deficit of neurones in cerebral and cerebellar cortex following early mild undernutrition. Arch Dis Child 46, 736-737.

16. Dobbing J (1964) The influence of early nutrition on the development and myelination of the brain. Proc $R$ Soc Lond B Biol Sci 159, 503-509.

17. Smart JL (1981) Under nutrition during early life and its effects on animal development and behaviour. Neuropharmacology 20, 1251-1252.

18. Morgane PJ, Austin-LaFrance R, Bronzino J, et al. (1993) Prenatal malnutrition and development of the brain. Neurosci Biobehav Rev 17, 91-128.

19. Barreto Medeiros JM, Cabral Filho JE, De Souza SL, et al. (2002) Early malnourished rats are not affected by anorexia induced by a selective serotonin reuptake inhibitor in adult life. Nutr Neurosci 5, 211-214.

20. Pine AP, Jessop NS, Allan GF, et al. (1994) Maternal protein reserves and their influence on lactational performance in rats. 4. Tissue protein synthesis and turnover associated with mobilization of maternal protein. $\mathrm{Br} J$ Nutr $\mathbf{7 2}$, 831-844.

21. Zamenhof S (1981) Maternal nutrient storage and efficiency in production of fetal brain tissue in rats. Biol Neonate 39, $45-51$.

22. Moita L, Lustosa MF, Tobias Silva AT, et al. (2011) Moderate physical training attenuates the effects of perinatal undernutrition on the morphometry of the splenic lymphoid follicles in endotoxemic adult rats. Neuroimmunomodulation $\mathbf{1 8}$, $103-110$

23. Chandler KD \& Bell AW (1981) Effects of maternal exercise on fetal and maternal respiration and nutrient metabolism in the pregnant ewe. J Dev Physiol 3, 161-176.

24. Dauge V (2003) Neurobiological impact of separating mothers from newborns in rodents. Med Sci (Paris) 19, 607-611.

25. Passos MC, Toste FP, Dutra SC, et al. (2009) Role of neonatal hyperleptinaemia on serum adiponectin and suppressor of cytokine signalling-3 expression in young rats. Br J Nutr 101, 250-256.

26. May LE, Glaros A, Yeh HW, et al. (2010) Aerobic exercise during pregnancy influences fetal cardiac autonomic control of heart rate and heart rate variability. Early Hum Dev 86, 213-217.

27. Clapp JF 3rd (2008) Long-term outcome after exercising throughout pregnancy: fitness and cardiovascular risk. Am J Obstet Gynecol 199, 489e1-489e6.

28. Deiro TC, Manhaes-de-Castro R, Cabral-Filho JE, et al. (2006) Sertraline delays the somatic growth and reflex ontogeny in neonate rats. Physiol Behav 87, 338-344. 